\title{
Improving the productivity of gas wells by stimulating "tight" formations - perspectives for continuation of exploitation in Transylvania basin
}

\author{
Diana-Andreea Lupu ${ }^{1, *}$, and Lazăr Avram² \\ ${ }^{1}$ Lucian Blaga University of Sibiu, Faculty of Engineering, Department of Industrial Engineering \\ and Management, Sibiu, Str. Emil Cioran, no.4, Romania \\ ${ }^{2}$ Petroleum-Gas University of Ploiesti, Doctoral School, Ploiesti, Blvd. Bucharest, no.39, \\ Romania ${ }^{2}$ Petroleum-Gas University of Ploiesti, Faculty of Petroleum and Gas Engineering, \\ Ploiesti, Blvd. Bucharest, no.39, Romania
}

\begin{abstract}
The current circumstances of exploitation of natural gas fields in the Transylvanian basin under the rehabilitation concept which aims to maximize the productivity of wells and implicitly increase recovery factors, justifies the assessment of new perspectives for further exploitation of Badenian formations, in which gas accumulations are classified as being tight gas reservoirs types. The concept of stimulating productivity using high pressures in the Transylvanian basin has remained under the significance of the research, therefore it is appropriate to resume analysis of identifying new production technology by integrating new geological data acquired and other geophysical investigations. The current paper presents through a case study the process of identifying a candidate well for stimulation based on the geological-technological considerations, and then, performing a technical-economical analysis to support the proposed program.
\end{abstract}

\section{Introduction}

The current circumstances of exploitation of natural gas fields in Transylvanian basin under the rehabilitation concept which aims to maximize the productivity of wells and implicitly increase recovery factors, justifies the assessment of prospects for further exploitation of tight gas fields.

High pressure stimulation is a technology that was tested experimentally between 1994 and 1995 in Transylvanian basin in the context of technical and informational constraints, and the results obtained offered the possibility of establishing an extremely valuable database and information.

From 1995 until today, the concept of stimulating productivity at high pressure in the Transylvanian basin has remained under research, which is why is considered that it is

\footnotetext{
*Corresponding author: diana.lupu@ulbsibiu.ro
} 
appropriate to resume analysis of this stimulation process by integrating the new geological and reservoir data acquired.

It is known that many gas production fields, initially, produce at rates that place them below the limit of economic profitability or often make it impossible to exploit them. The innovations brought in high pressure technology domain (fluids, equipment, proppant) have allowed, especially in recent years, the use of energy held by so-called unconventional reservoirs. In the current context of increasing global reserve replacement rates, the option of exploiting unconventional reservoirs is a viable alternative for many hydrocarbon producing companies. The theoretical aspects of the high pressure stimulation, as a method of stimulating the productivity of wells, have been substantiated by many scientific papers published in the literature at international and national level [1].

\subsection{Geological-technical considerations regarding the selection of candidate wells for high pressure stimulation operations}

The process of selecting the candidate wells for the high pressure stimulation operation is a complex one and involves, in general, the correlation of some geological and technical considerations, these being synthesized in Figure 1, and some of them detailed below as follows:

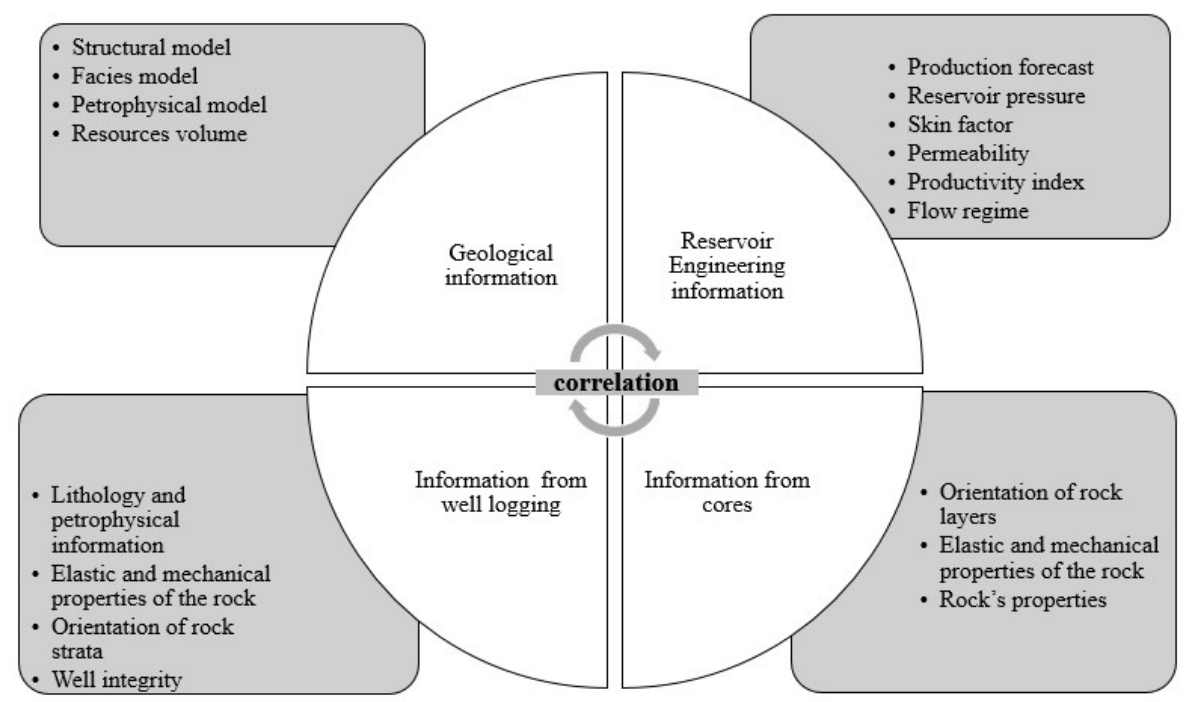

Fig. 1. Geological-technical considerations involved in the selection process of the candidate wells for the high pressure stimulation operation.

Geological information are related, in particular, to the structural model, the facies model and the petrophysical model of the reservoir. The shape and extension of the reservoir, respectively the type of the trap have a determined role in choosing the candidate wells for high pressure stimulation in the sense that the length (xf) and the height of the fracture (hf) are designed according to these elements. The facies model provides information on the arrangement of the lithological sequences and the orientation of the layers, this information being useful both in choosing the fluid, but also in the geometric modelling of the operation. The petrophysical model from the perspective of permeability distribution has an influence in the elaboration of the wells production forecasts and on the simulation process of the high pressure stimulation. 
Reservoir engineering information and well testing data are important from the point of view of evaluating the productive potential of the wells. The volume of the gas reserves and the productivity index related to the candidate wells are performance indicators with a decisive role in carrying out the high pressure simulation operation. Permeability, skin factor and reservoir pressure are key technical factors in the operation design and evaluation process. These parameters are determined through a well testing program, performed before and after the stimulation operation $[2,3]$.

Direct analyses performed on mechanical cores extracted from geological formations of interest contribute substantially to the determination of the elastic and mechanical properties of the rock: Young's modulus, fluid loss coefficient, stress gradient, fracture strength etc.

The results of the interpretations of the geophysical well logs are decisive in the process of selecting the wells for the high pressure simulation operation. In order to select a well for high pressure simulation, in addition to the conventional logs (Gamma Ray, Caliper, Dual Laterolog Density, Sonic and Neutron), special investigations are required. The special investigations related to sedimentation and tectonics have the role of highlighting elements of stratification and layer orientation and elements of layer deformation (faults and folds). The geophysical investigations related to the anisotropy of the rock have the role to highlight its mechanical and elastic properties such as stress and tension of the rock, Poisson's ratio, Bulk modulus, Shear modulus and Young modulus, properties necessary for building the mechanical model of the reservoir. Geophysical investigations related to the integrity of the well construction allow the evaluation of potential technical problems that may occur during the operation.

Analysing and correlating all data and information in an integrated way will lead to the selection of the best wells for the high pressure simulation operation.

A considerable amount of data is needed to design the hydraulic stimulation operation, and their correctness will be an important aspect in obtaining an efficient stimulation model. Uncertainties or limitations related to certain data and information may compromise the results of high pressure simulation operations, which is why a technical and economic risk analysis is required before selecting the well.

\subsection{Lessons learned from stimulation campaign performed in Transylvania basin}

In the period 1994-1995, some natural gas fields from Transylvanian basin were under an extensive program of research, testing and analysis using high pressure stimulation technology, which included 8 operations. The wells included in the research program exploited geological formations of Badenian age and very few of Buglovian and Sarmatian age.

The main objective of program was primarily to research and evaluate the high pressure technology and to increase the productivity of wells.

The stimulation technology applied to most wells consisted in the use of water-based linear fluids whose main composition was guar hydroxypropyl (HPG) with an average concentration of $3.5 \mathrm{~kg} / \mathrm{m}^{3}$ of polymer, and as additives were used gel breakers, clay stabilizers $\left(0.24 \mathrm{~kg} / \mathrm{m}^{3}\right)$, alcohols $(5 \%)$, bactericides and foam breakers. During this campaign, a $\mathrm{CO}_{2}$-based fluid was used in a well and the results obtained after stimulation were appreciable.

Following the campaign, the cumulative gas flow of the wells increased by approx. $77 \mathrm{kscm} /$ day. Comparing the total gas flows before and after the stimulation, daily production increased with $16 \%$. The success rate of the experimental campaign to test the high pressure stimulation technology was about $32 \%$. This performance indicator cannot be 
neglected, on the contrary it is an encouraging value and requires the continuation of research and testing of existing high pressure stimulation technologies in industry in order to identify the most appropriate and efficient solution for Badenian reservoirs in the Transylvanian basin, which are a tight formation (reservoir permeability is below $1 \mathrm{mD}$ ) .

Following this experimental campaign to test the stimulation technology, the specialists involved in the research program highlighted some aspects that need to be considered in order to optimize future stimulation operations, as follows [4]:

- The Badenian formations in the Transylvanian basin are characterized by a lithological contrast, which indicates that the stimulation technology must be carefully selected. Careful laboratory investigations have shown that polymeric aqueous fluids are not indicated for reservoirs in the Transylvanian basin due to the blocking effects and capillary effects that can be induced by these fluids [5].

- The Badenian and Buglovian formations are not homogeneous, they are formed by an interbedded sands with shale, constituting hydrodynamic units of multi-layered type. This, can lead to the creation of fractures in directions that are difficult to control, which can put in communication areas with high water saturation, which subsequently lead to a decrease in the productivity of the well. The mineralogical components must be carefully analysed as it has been shown that clay intercalations have a high retention of stimulation fluids.

- The value of the static reservoir pressure must be above 100 bar to ensure an efficient cleaning of the stimulation fluids, respectively to avoid the creation of additional pressure drops in the reservoir by retaining the fluid in the rock pores.

- The integrity of the well must be known with sufficient accuracy, respectively the technical condition of the casing and the adhesion of the cement behind it must be good because otherwise the fracture will propagate on directions where an aquifer which can be connected with the fracture, or a zone with very high water saturation.

- The effective thickness of the productive layer should be between 10-15m.

- The accuracy and availability of data is critical and supports the modelling and simulation of the stimulation operation. In this campaign the design was based on primary data from seismic, drilling, cores, geophysical investigations, hydrodynamic research and information from mini-frac tests, which allowed the creation of structural, petrophysical and geo-mechanical models for only 3 wells. The data were considered insufficient, but provided, to some extent, support in assessing the productive potential, geometry and orientation of the fractures, the stimulation fluid and the proppant

The conclusions of this campaign are that the application of stimulation technology in the Transylvanian basin is still a challenge, even if the results obtained from the experimental campaign were not as expected. This type of treatment should not be excluded from the portfolio of technological options to increase the productivity of wells. The database completed following this experimental campaign is a very valuable one and must be materialized by continuing research related to high pressure stimulation technology, which has improved and adapted considerably in recent years depending on the particularities of the reservoirs.

The success rate of $32 \%$ is acceptable and even encouraging to look for new prospects for further exploitation of Badenian age reservoirs by applying high pressure stimulation technology. The small recovery factors at the level of the Badenian formations require a different technical approach and indicate to us at this moment that it is necessary tointegrate the lessons learned with the newly acquired information and the technological progress in the field of investigations.

It is believe that the technical perspectives for capitalizing on the energy potential of unconventional reservoirs in Badenian are related to high pressure stimulation, therefore, a case study will be presented below regarding the technological solutions to 
continue the gas exploitation in Transylvanian basin.

\section{Case study- Identification of a candidate well for high pressure stimulation on a gas field located in the northern group of the Transylvanian Basin}

\subsection{Reservoir description}

From the analysis of the production history of a commercial gas field located in the northern group of the Transylvanian basin, it was observed that the wells produce at low gas rates (between 3.5-5 kscm/day - Figure 2), respectively the flow of fluids from the reservoir into the well is performed based on a high pressure drops. The structure consists of multi-layered reservoirs grouped in 26 productive complexes, mostly of Badenian age, whose depth is between $1700-2580 \mathrm{~m}$. The permeability of the reservoir rocks between $0.01-0.7 \mathrm{mD}$ (see Figure 3).

Due to the low productivity of the wells, the reservoirs have very low current recovery factors $(<40 \%)$, although the exploitation started in 1978 .

At the same time, it was noted that the current reservoir pressures are between 60-210 bar (Figure 4), the pressures confirming the existence of energy potential in Badenian formation.

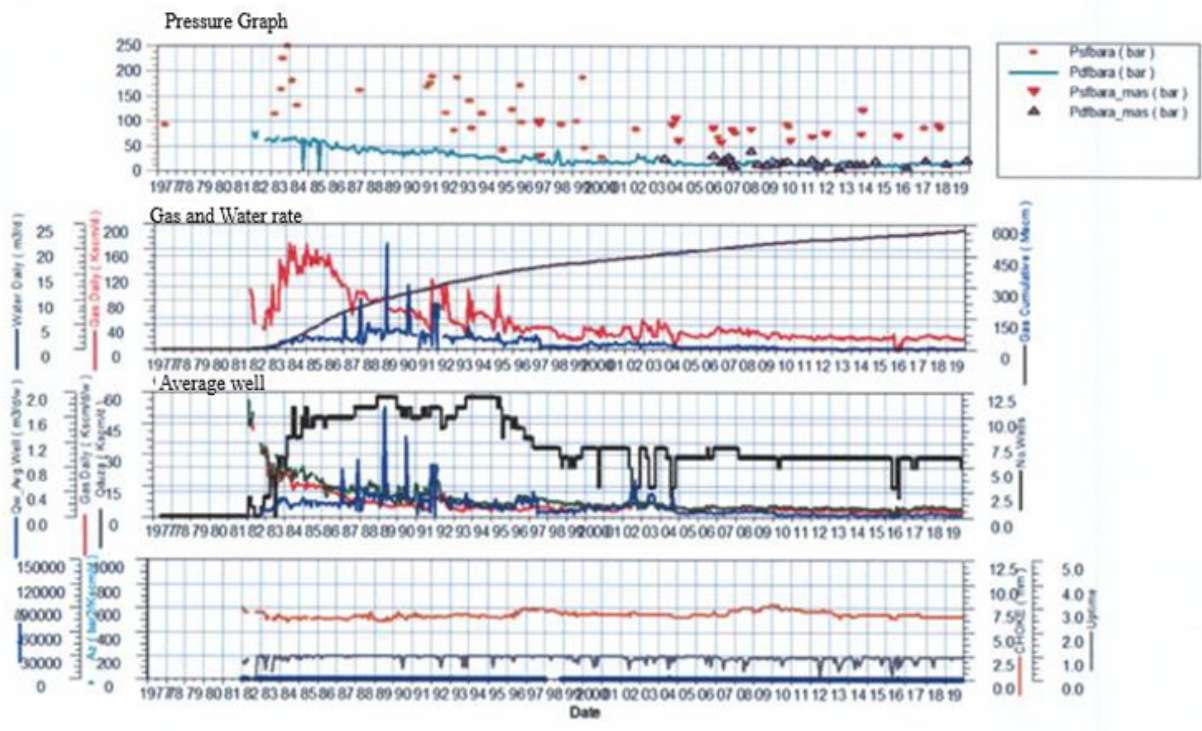

Fig. 2. Production history of the field. 


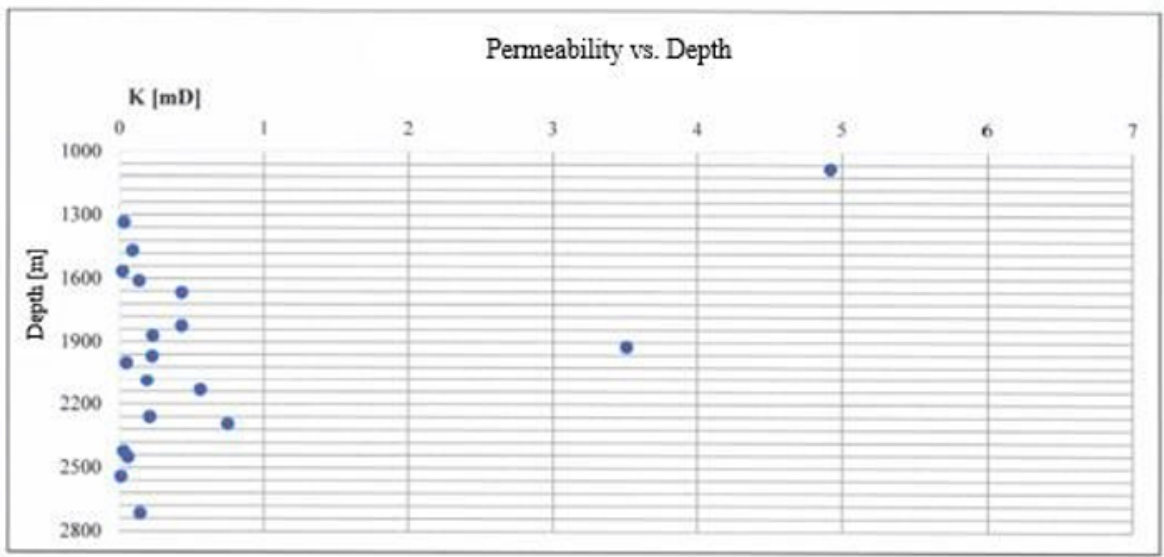

Fig. 3. Reservoir permeability vs. depth.

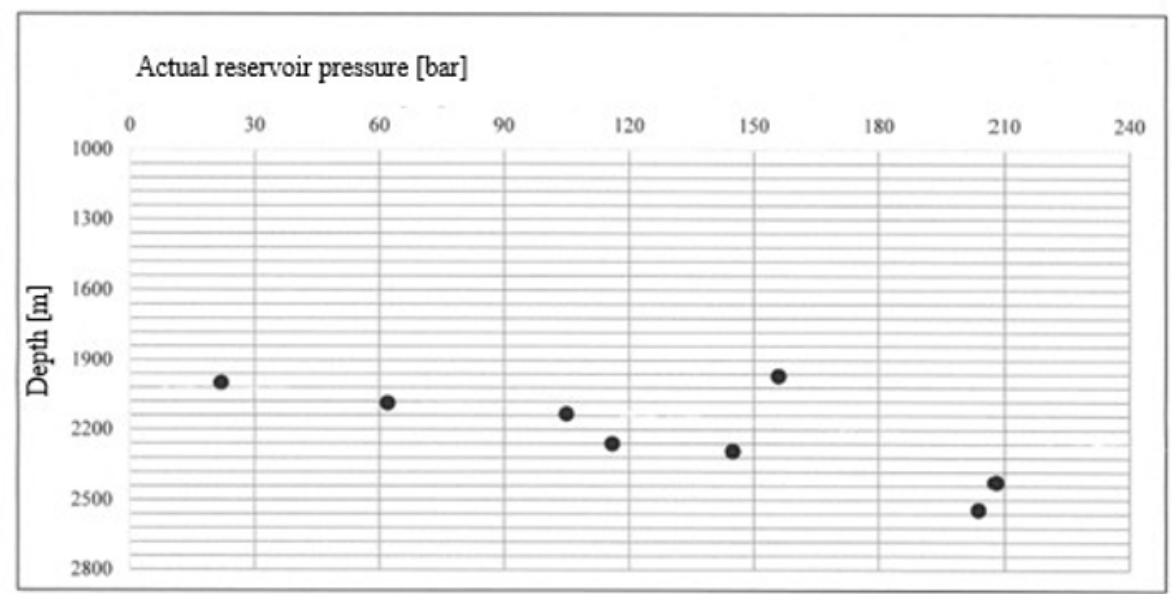

Fig. 4. Reservoir pressure vs. depth.

Integrating the field data with the criteria for selecting a well for high pressure stimulation treatment, it was identified that the Omega well that produces the Lcomplex is a good candidate for this type of operation. Figure 5 presents a fragment from the log of the correlation well of the field in which all the productive complexes are highlighted. It is noted here that at the level of the L complex, located at a depth of $2465-2534 \mathrm{~m}$, the permeability is $0.06 \mathrm{mD}$ and the porosity is $5.8 \%$.

The Omega well was drilled in 2005 and was put into production at Badenian formation, complex L, opening the selective interval $2563-2528,5 \mathrm{~m}, 2522-2514 \mathrm{~m}, 2501$ $2495 \mathrm{~m}$ (total $21.5 \mathrm{~m}$ ). The initial production parameters were: reservoir pressure 275 bar, choke size $6 \mathrm{~mm}$, tubing/casing pressure 12.7 / 29.5 bar, field pressure 4 bar, gas rate $6.4 \mathrm{kscm} /$ day, water rate $0.01 \mathrm{~m} 3$ /day.

The well had a relatively constant production behaviour, the gas rate was maintained at $2.7-3 \mathrm{kscm} /$ day, the water rate $0.001 \mathrm{~m} 3 /$ day on a choke size of $7 \mathrm{~mm}$. The current recovery factor at the level of the L complex is about $29 \%$.

The well is producing under a pressure drop of 183 bar, under the conditions of a current static pressure of 204 bar and a bottomhole flowing pressure of 21 bar. 


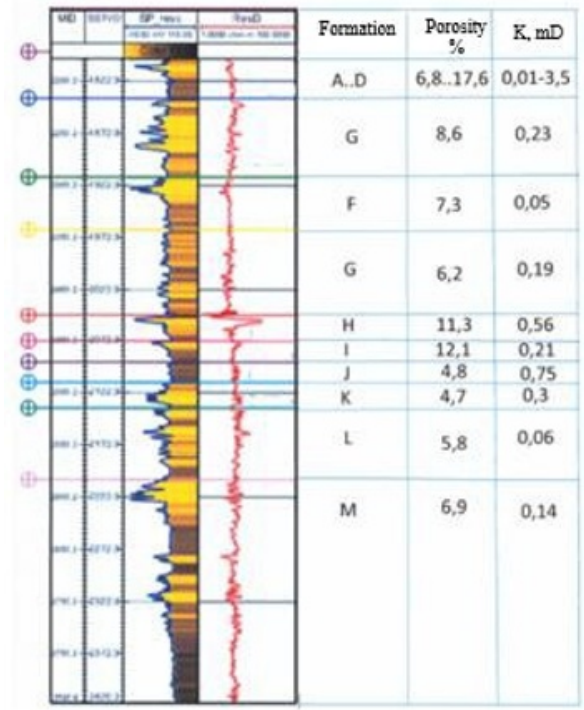

Fig. 5. Correlation log of the field.

In view of the above-mentioned aspects, the operation of high pressure stimulation of the L- complex in the Omega probe aims to achieve the following objectives:

- Intensification of production and increase of the recovery factor,

- Increasing the conductivity of the reservoir,

- Reduction of operating expenses,

- $\quad$ Increasing the productivity index.

\subsection{Geological-technical criteria for well selection}

The Omega well is positioned at the apex of the structure at the level of the Badenian formation, complex L (Figure 6), at a distance of about $260 \mathrm{~m}$ from the Gamma well which exploited the formation between 1984 and 1991 and extracted a cumulative gas of 14.4 mil.mc.

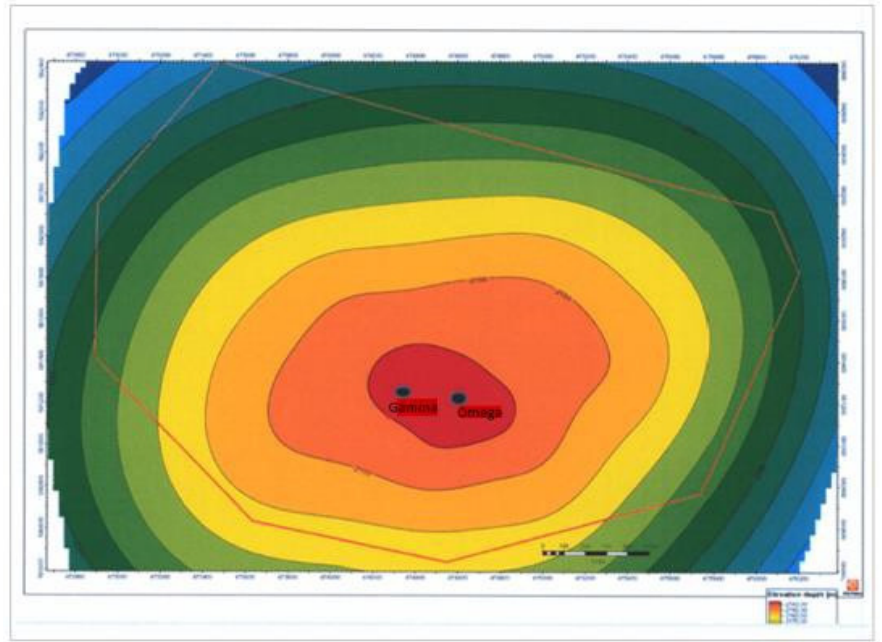

Fig. 6. Structural map of the Badenian L (well Omega). 
From a lithological point of view, the reservoir rock in the L complex consists of a very well cemented sandstone (tight type formation), whose permeability is below $0.2 \mathrm{mD}$. The estimated value for permeability is based on geophysical investigation.

The estimated current reservoir pressure is approx. 204 bar and the drive mechanism is gas expansion.

From the point of view of the integrity of the well construction, to determine the technical conditions of the casing, MIT- Multifinger Investigation Tool and an investigation to evaluate the adhesion of the cement behind the casing (RBT-Radial Bond Tool) is required.

In Figure 7 are highlighted the intervals proposed for high pressure stimulation expressed in SSTVD.

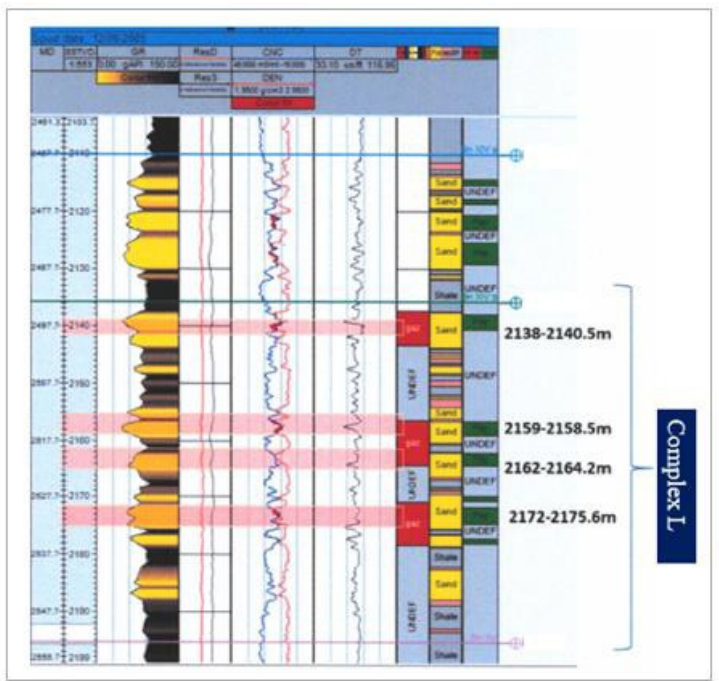

Fig. 7. Section from Omega well log.

\section{Productivity analysis of the well}

To determine the productive potential of the well a nodal sensitivity analysis was performed, by varying the value of the skin factor. Figure 8 shows the results of nodal analysis of skin factor variation.

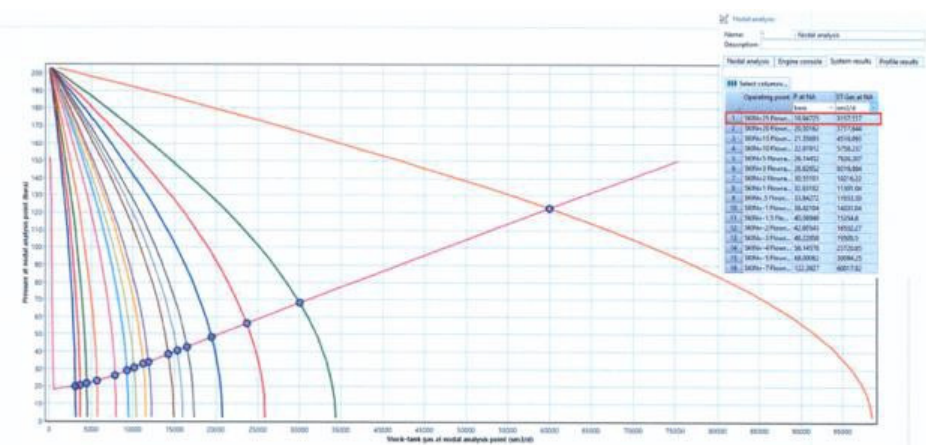

=:

Fig. 8. Nodal analysis to determine the productive potential of Omega well by variation of skin factor. 
In the current operating context, the skin formation factor is estimated at 25 , at a bottomhole flowing pressure of 21 bar and a reservoir pressure of 204 bar, with a gas rate of $3 \mathrm{kscm} /$ day. The flow equation used was Darcy's.

The variation of the skin factor, S, resulted in a series of performance curves, but for the production forecast it was admitted the existence of two options for continuation of the exploitation of well Omega, namely:

1. The conventional option - the scenario through the exploitation of Omega well without interventions will be continued. The limit year of the production provision is 2042, and the estimated gas volume is 13 million $\mathrm{m}^{3}$.

2. High pressure stimulation option - for this scenario, a volume of gas of 17 million $\mathrm{m}^{3}$ was estimated for all three probabilistic scenarios analyzed, this volume being a minimum one for the operation to be profitable:

- Scenario P90 - the scenario considered pessimistic in which the gas rate increases from $2.7 \mathrm{kscm} / \mathrm{d}$ to $8 \mathrm{kscm} / \mathrm{d}(+5 \mathrm{kscm} / \mathrm{d})$, with an estimated skin factor of 15 after the high pressure stimulation operation.

- Scenario P50 - the scenario considered realistic in which gas rate would increase from $2.7 \mathrm{kscm} / \mathrm{d}$ to $14 \mathrm{kscm} / \mathrm{d}(+11 \mathrm{kscm} / \mathrm{d})$, with an estimated skin factor of -1 , after the high pressure stimulation treatment.

- Scenario P10 - the optimistic scenario in which gas rate would increase from $2.7 \mathrm{kscm} / \mathrm{d}$ to $17 \mathrm{kscm} / \mathrm{d}(+15 \mathrm{kscm} / \mathrm{d})$, with an estimated skin factor of -2 , after the stimulation treatment.

Figure 9 illustrates the production forecast made by the method of production decline. It is noted that for the same volume of gas, the stimulation treatment intensifies the production and reduces the operating period.

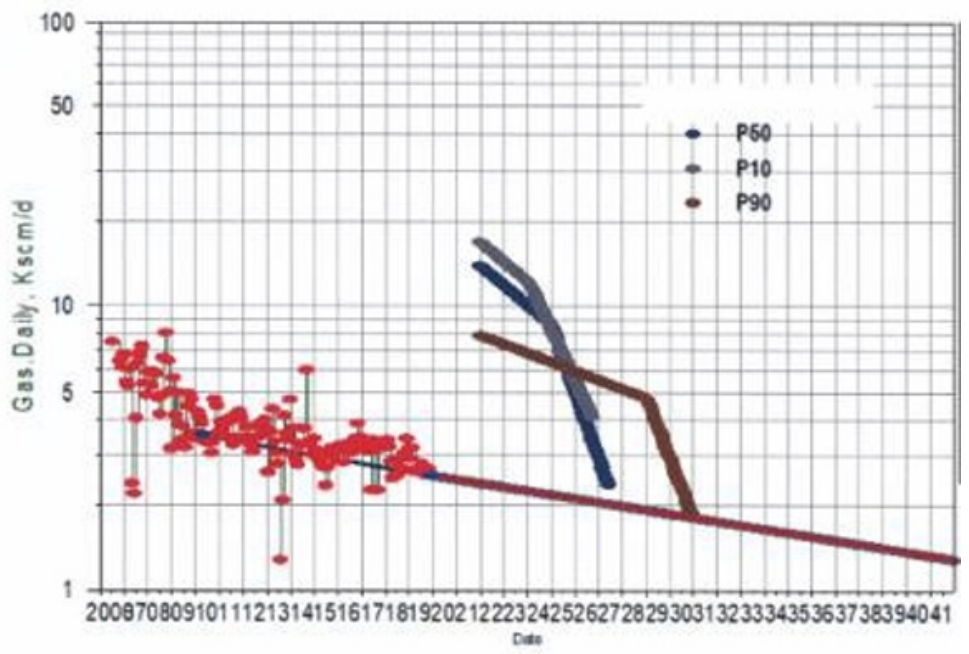

Fig. 9. Production forecast for well Omega.

In order to determine the economic efficiency of the stimulation operation of the Omega well, a comparative cash flow analysis was performed between the conventional and the stimulation option (P50). The following resulted:

- $\quad$ Conventional option- The resulting net present value is NPV $=693500$ USD.

- $\quad$ High pressure stimulation option (P50)- the value of the investment is 1350

000USD. The resulting net present value is NPV $=1054420$ USD. 


\section{Conclusion}

In conclusion, following this analysis it can be admitted that stimulation treatment intensifies the exploitation and the recovery of reserves is achieved in a much shorter period of time compared to conventional exploitation, in favourable economic conditions.

\section{References}

1. M.V. Batistatu, F. Dinu, F., Actual trend in Romania's mature oilfield exploitation, Technical series, Petroleum Gas University of Ploiesti, vol. 62 (2010)

2. M.Cristian, S. Socol, A. Constantinescu, Creşterea productivităţii şi receptivităţii sondelor, ( Editura Tehnică, 1982)

3. D.P. Ştefănescu, D.A. Lupu, Improved recovery techniques and methods used to stimulate the well production based on reservoir characteristics, 18th International Multidisciplinary Scientific GeoConference SGEM , Bulgaria, Vol. 18, Mineral Processing,Oil and Gas Exploration, ISSN 1314-2704, DOI 10.5593/sgem2018/1.4/S06.063, p. 475-482 (2018)

4. D.A. Lupu, I. Foidaș, Lessons learned during the fracturing campaign performed in Transylvanian basin, Symposium of Society of Petroleum Engineers Romanian Section, https://www.speromania.org/, , Mediaş, Romania (2017)

5. M. Florea, Contribuții la îmbunătăţirea tehnologiei extracţiei fluidelor din sondele de gaze naturale, Doctoral thesis (in Romanian), p.66-78 (2010) 